\title{
National Open University Education Resources Construction Research Based on Cloud Computing
}

\author{
Yang Jing \\ Zhuhai City Polytechnic, Guangdong, Zhuhai, 519000
}

Keywords: Cloud computing; Resources construction; National Open University

\begin{abstract}
Open University learning environment need to adapt to the aim of Open University education and the objective demand of students. The construction of cloud platform is to build a new information interaction platform for open education. This paper analyzes the feasibility of cloud computing applied to National Open University education resources construction, puts forward thesystem design construction of national Open University education cloud platform, in order to promote the construction of Open University network education resources and improve the level of Open University education.
\end{abstract}

Fund project: This paper is one of the contributions of "Open University resources construction mode study in cloud computing environment", which is aGuangdong open and distance education scientific research foundation project (Item number: YJ1308).

\section{I.Introduction}

The emergence of cloud computing puts forward a new train of thoughtto solve current Internet data volume growthcomputing problems and improve the ability of data storage. As a new information service mode, the application of cloud computing in education industry will largely promote the education information resources sharing. From high quality resources integration to education cloud construction, education informatization construction will meet a new situation, which is restructuring and optimization ofseveral kinds of information resourcesby education cloud to achieve a wide range and high efficiency of resource sharing. At this stage, the quality research of open education teaching has become an important force in open education reform, and has made an important contribution to the development of open education. As an important dimension ofopen education reform, the application of modern information technology has become an important support to improve the quality of teaching. Open education of the 21st century will develop in the direction of more open, and technological progress is a major means of making learning more open.

\section{Cloud computing technology application feasibility in national Open University education resources construction}

A.An overview of cloud computing technology

Cloud Computing is the conceptGoogle CEO Eric schmidtfirst put forward in 2006 search engine meeting. Cloud Computing is a fusion product ofGridComputing, distributed Computing, Parallel Computing, Utility Computing and Network Storage Technologies, Virtualization, Load Balance and other traditional computer technology and Network technology development, which is an emerging business Computing model.

At present, three main forms of cloud computing services are: Infrastructure as a Service (IaaS), Platform as a Service (PaaS), and Software as a Service (SaaS). IaaS service mode is to merge multiple servers' memory, I/U equipment, computing power and storage into virtual resource pool, and then according to the need to provide users with storage resources and virtualization server. PaaS takes the development environment as a service to provide.Users can customizetheir own application based on platform to develop and transfer to others through the server and the Internet. SaaS refers to the unified deployment of application software, and the usersorderapplication 
software they need through the Internet.

B.Current and inadequate situation of national Open University education resources construction

National Open University is established on the basis of CentralRadio and Television University and Local Radio and Television University, supported by modern information technology.The school network is three-dimensional and covers nationwide urban and rural areas. It values education and non-academic education, gearing to the needs of all members of society, and it is a new type of university without walls. At present, the registered students enrolled are 3.59 million people. National Open University (Central Radio and TV University) current network teaching support environment uses"triple platform interaction" architecture. Namely, central radio and television university, 44 provincial television university and 929 city-level radio and television university respectively have their own network computer room, database, access to the Internet through different Internet media; provincial TV university and central radio and TV university cities make three-stage teaching platform installation in their respective network computer room on the server. The original intention of"Triple platform interaction" type network teaching environment design is to enable learners get to nearly 1000 network teaching platform in order to solve the issue of network congestion and the load stress on the server. But this kind of design pattern exist the following problems:

(1)Many repetitive resources constructions: all levels of TV universities greatly satisfy the distance education development of the region, put money into building, but they are open to each other to form information islands, three-stage teaching platform statistics cannot realize integration and synchronization, and cannot realize resources sharing. Often, there areefficiency distribution load imbalance, high quality resources imbalance, teaching platform traffic scarce, some teaching platform network and storage equipment load stress, and so on and so forth.

(2) Require learners' multiple logins: because of 3level platforms interactive constructionrequires learners multiple logins when they visit learning resources. And there isno planning system between nearly thousand teaching platforms education resources construction, so platforms teaching content lacks consistency and guides, which willeasily lead to confusion when learners use learning resources.

(3) Lack of technical support: technical forcesdistributed in nearly thousand teaching platforms are uneven, which is hard to safeguard the comprehensive teaching support for teachers "teaching" and students "learning".

C.The meaning of cloud computing applied to national Open University education resources construction

Distance education system based on cloud computing can provide more powerful support service ability, which is very suitable for large-scale open distance education. Cloud computing application significance in distance open education mainly embodies in the following aspects:

(1) Reduce the national Open University funding system: cloud computing can use very cheap nodes to form a cloud, and achieve huge amounts of computing power and the ability to deal with huge amounts of data analysis. Remote education system based on cloud computing has no longer a certain requirements of high-performance servers, which can be made at all levels across the country, the server or even an ordinary computer cloud to provide high performance services, saving computer hardware equipment investment.

(2) Improve the capacity of resource sharing and remote support services: based on cloud computing model, national Open University can establish a nationwide unified teaching resource management system in open education campus, provide unified deployment at provincial and municipal education technology center, and unified service for national Open University students to realize teaching resources sharing. In addition, according to cloud computing flexible customization, every Open University students can find the most efficient, most high-speed access path, and find teaching resources for learning. Deploy remote education system on cloud service environment to make the best use of remote education system of concurrency and interaction for more real-time, streaming smoother, faster access speedinteraction between teachers and students.

(3) Improve reliability and security.Cloud computing services are on different servers.If one 
node has problem, check it, and automatically start another redundant node to ensurenormal application and calculation, which greatly improves the reliability and security of the system.

\section{The national Open University education resources system design based on cloud computing}

Based on open and distance education concept and characteristics of cloud computing, we need to combine the following points for the construction of open education cloud system.

A.National Open University education cloud platform architecture design

There are very rich texts and video multimedia resourcesin Open University remote education system, and these resources ask for a higher, faster computing power and storage capacity service system. Corresponding to the cloud platform's three services forms SaaS, Paas, IaaS, and Open University education cloud platform architecture is divided into three levels: infrastructure layer, platform layer, and application layer software. Platform overall architecture is shown in Figure 1:

(1) Infrastructurehardware part including servers, storage systems and network systemsprovides basic hardware platform service through virtualization technology, which can provide high performance computing for open learning and great capacity of information storage, and is the foundation of the whole open learning cloud. National Open University infrastructure cloud construction consists of two parts: one content is based on the existing central rtvu teaching system and national digital learning resource center for hardware cloud platform construction; the other content is integrated part of Open University campus hardware resources, which increases the elasticity of the expansion of cloud computing center, and further embodies the value of cloud computing technology.

(2) Platform service includes authentication, authorization, data management platform service system, which is mainly composed of middleware, database and development platform, and can be effectively interacted and store data. In platform service, pay attention to provide a complete middleware and diversified interface, and access conditions of all kinds of resources for local Open University.

(3) Software services are the top service of educationcloud, which is a core part of education cloud. Education informationization system deployment is in the layer.Through the unified portal, provide services, users the service entrance. On the service platform, students can learn by learning guidance to find the right resources; Through network course, form a complete set of resources for learning; Through curriculum development, track resources frontier development knowledge; Through curriculum forms such as BBS, online communication, make interactions between teachers and students and students and students; By studying self-test and formative assessment model, get learning feedback. 


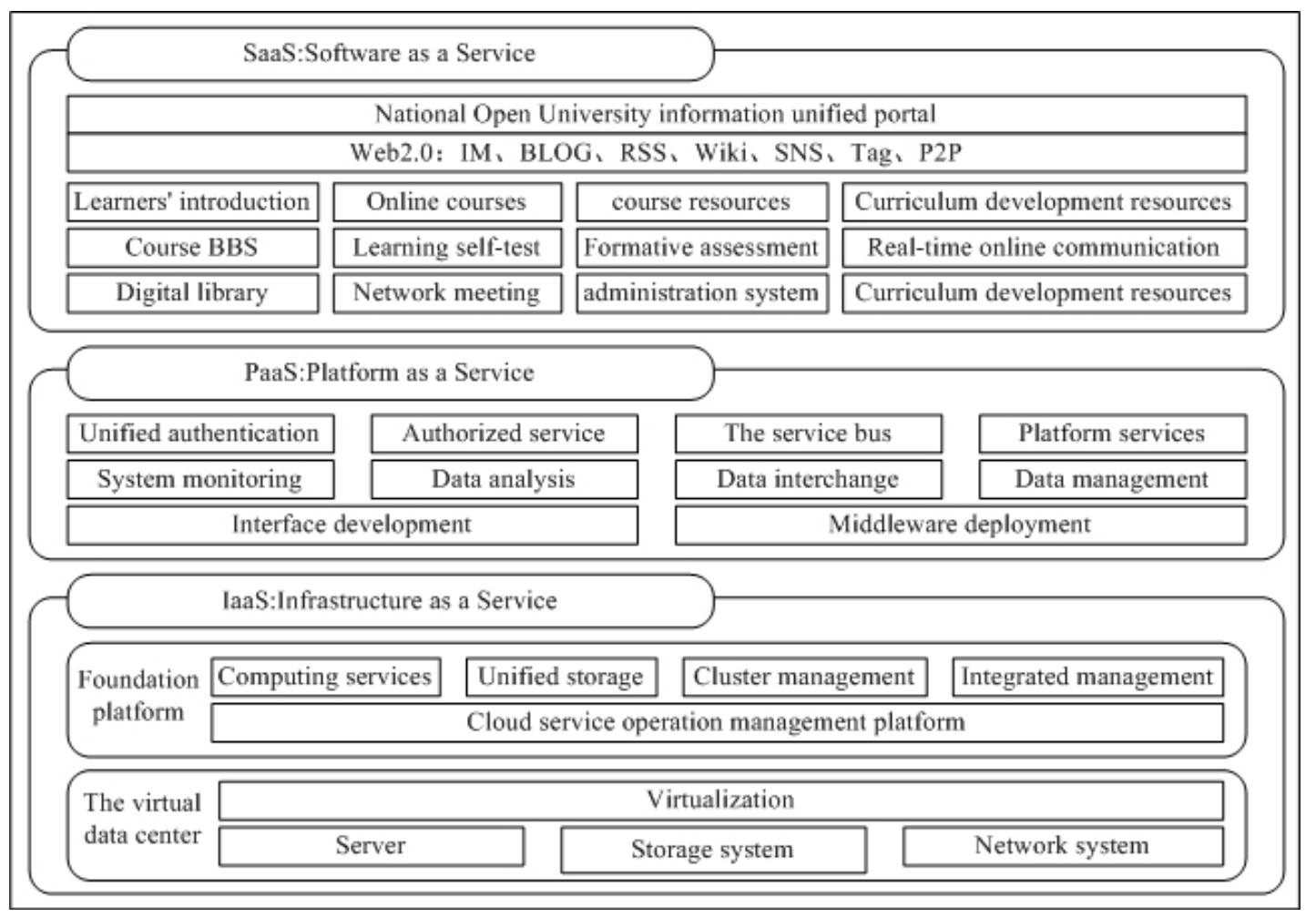

Figure 1 National Open University education cloud platform overall architecture diagram B.National Open University education cloud platform logical structure design

The logic structure diagram of National Open University education platform based on cloud computing is shown in Figure 2.All levels of resource sink into national Open University cloud platform, and students receive resources according to the requirement, participate in virtual classroom teaching, and form a study group without limited geographical location. In this logical structure: (1) Pay attention to create virtual learning community and virtual classroom: under cloud computing, all resources and applications will be integrated in the "cloud"; each student can take advantage of these resources and applications to create virtual community of freedom, and are not limited by space environment. They have the freedom to build their own virtual learning environment, together with other learners, have common learning goals for collaborative learning. (2) Pay attention to carry out mobile learning: especially in the popularity of smart phones today, remote education paysmore and more attention to fragmentation of knowledge material, and forms a complete set display model with smartphones for teaching. 


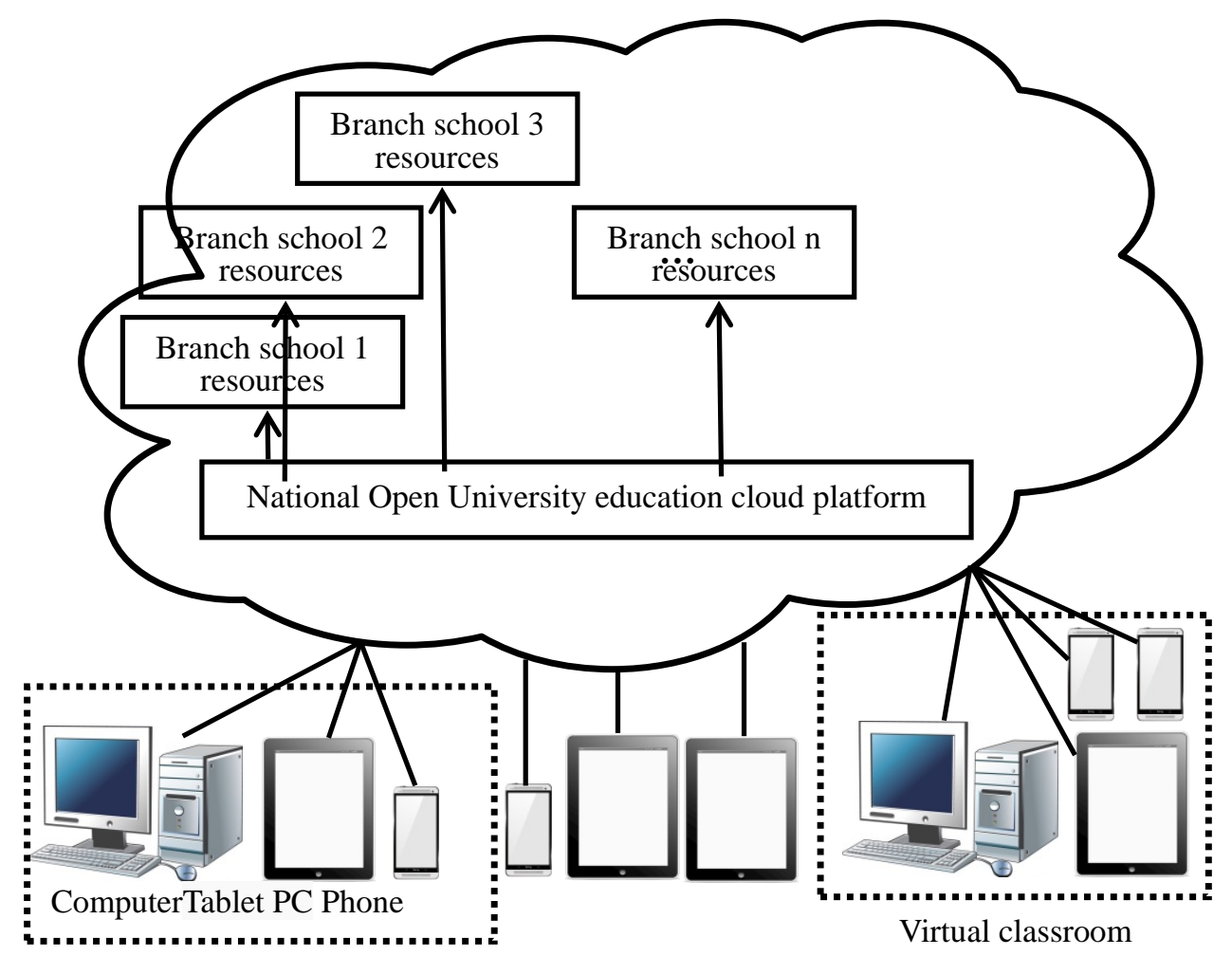

Study group

Figure 2 National Open University education cloud platform logic structure

C.National Open University education cloud platform technical characteristics

Based on the above background,national Open University education cloud platform put forward should have the following technical features:

(1) Support resources dynamic extension

Resource dynamic flow means to realize resource scheduling mechanism under cloud computing platform, and resources can flow to where it is needed. In national Open University education system, themost of audience are part-time students, so learning time is relatively concentrated in the evenings and weekends. The technical features of support resourcesdynamic extensions, therefore, can concentrate in access to resources, start the idle resources into the system, and improve the bearing capacity of the entire cloud platform; get weekdays and summer and winter vacations together, and put the idle resources into energy saving mode. Both can enhance peak processing capacity, and can achieve green resources with the application of low carbon effect.

(2) Support vast amounts of information processing

Cloud computing will inevitably need to face huge amounts of information interaction.It needs efficient and huge amounts of stabledata communication and store system as support. Through cluster deployment OSD (Object -based storage Device) and MDS (Metadata server), at the same time allocation of large capacity, high performance and high scalability DFS (Distributed File System) provides cloud storage service way so as to realize its infinite elastic expansion on the capacity and performance.

(3) Supportvariety of resourcescloud service operation management such asIaaS, PaaS, SaaS

Because many national Open University campuses branch schools have different teaching strength and technical strength, education resource construction has different starting point in the cloud platform. So, opena variety of cloud resources service mode, such asIaaS, PaaS, SaaSto branch schools is better than a single open SaaS to adapt to different teaching environment. Therefore, in the design of platform architecture, divide three levels of cloud servicesmodes corresponding branch schools' resources construction, and open a unified portal publishing resources to learners.

(4) The platform is designed based on service-oriented (SOA) software architecture, follows ITIL service management methodology, and provide various types of cloud services by way of 
Web2.0, which has a better user experience and information sharing, and the cloud service resources can be search out more conveniently and are available for use. Based on cloud service repository, build efficient reusable component library service resource management, and achieve more efficient and fast, low cost resource integration and deployment model.

\section{Conclusion}

National Open University education cloud platform can provide quick and convenient services to open learners to achieve resource sharing, and virtualization technology, which reflects the basic concept of cloud services, and it is theoretically feasible. While the current cloud computing cannot perfectly solve all the problems, such as how to coordinate campus infrastructure resources construction of branch schools, domestic network environment is not ideal, cloud resources construction standards and promotion and so on. But continuoustry and innovationwill play a huge role in promoting the development of open and distance education.

\section{References}

[1] Fang Yuexin. The Key Points and Difficulties in Building The Open Education Cloud System, Journal of Lishui University, vol. 35, no. 5, pp. 65-70, 2013.10.

[2] Wang benbiao. Research on the Learning Resources Construction of the Open Education -based on Cloud Computing, Journal of Anhui Radio \& TV University, pp. 71-74201-3.4

[3] RuanJinbo.Cloud computer technology application in modern open education, China Management Informationization, il. 17, no. 10, pp112-113, 2014, 5.

[4] Li Xiaosan.Shallow discussion on the application of cloud computing technology in distance open education, Journal of Xinjiang Radio \& TV University, vol. 15, no. 51, pp. 62-65201-1.1

[5] Zhao Yanping.Cloud computing influenceon mobile learning resources in open education.Fujian Computer, pp. 194-196, 2014.1.

[6] Yu Guanjie, Feng Qi.Cloud computing technology application in open education in radio and TV university. Industrial \& Science Tribune, vol11, pp. 147, 2012, 1.

[7] Zhang Song, Liu Chengxin, Chang Yu. Cloud computing in Education technology research review in China. Journal of Beijing Institute of Education (Natural Science Edition), vol. 8, no. 4, pp. 33 to 39, Dec, 2013

[8] RenYouqun, XuGuangtao, Wang Mei, Promoting Qualified Educational Resource Sharing with ICT: From the Perspective of System Science, vol. 19, no. 5, pp. 104-111, 2013.10. 